\title{
The Use of $\mathrm{Br} / \mathrm{Cl}$ to Promote Regioselective Gold-Catalyzed Rearrangement of Propargylic Carboxylates: An Efficient Synthesis of $(1 Z, 3 E)-1-B r o m o / C h l o r o-2-C a r b o x y-1,3-D_{i e n e s}+, \neq$
}

\author{
Yanzhao Wang, Biao Lu, and Liming Zhang ${ }^{\star}$ \\ Department of Chemistry and Biochemistry, University of California, Santa Barbara, CA 93106.
}

\section{Abstract}

A gold-catalyzed synthesis of 1-bromo/chloro-2-carboxy-1,3-dienes is developed using propargylic carboxylates containing halogenated alkynes as substrates. The reaction is highly diastereoselective, and the halogen atom at the alkyne terminus promotes selectively 1,2-acyloxy migration. The diene products participate in the Diels-Alder and cross-coupling reactions.

Propargylic carboxylates are versatile substrates for gold catalysis, ${ }^{1}$ and various synthetically valuable structures can be synthesized. These gold-catalyzed reactions typically proceed mechanistically through one of two competing reaction pathways, i,e., 3,3rearrangement ${ }^{2}$ and 1,2-acyloxy migration ${ }^{3}$ (Scheme 1). ${ }^{4}$ The preference for either pathway and the eventual reaction outcomes are mostly determined by substrate structures: $3,3-$ rearrangement typically occurs with internal alkynes, and 1,2-acyloxy migration is usually limited to substrates derived from tertiary or benzylic alcohols containing terminal alkynes. An exception was our earlier study that took advantage of the equilibrating nature of these two pathways. ${ }^{5}$ An important class of propargylic carboxylates, i.e., those derived from secondary aliphatic alcohols containing terminal alkynes (e.g., 1, Scheme 2) are notably missing in these much studied gold-catalyzed reactions, thus to a significant extent limiting their synthetic utilities.

To overcome this substrate scope limit, we envisioned that the attachment of an electronegative halogen to the alkyne terminus ${ }^{6}$ of $\mathbf{1}$ (i.e., 2) would not only activate the alkyne toward nucleophilic attack but also render such attack regioselective at the alkyne distal end as positive charge development at the proximal end upon gold activation is destabilizing (comparing structures $\mathbf{A}$ and $\mathbf{B}$ in Scheme 2); ${ }^{7}$ consequently, a 1,2-acyloxy migration would be selectively facilitated. While propargyl $t$-butyl carbonates with terminally halogenated alkynes have been studied with gold catalysts, ${ }^{8}$ to our surprise, related propargyl carboxylates have not been employed in gold catalysis although the inclusion of a halogen atom offers foreseeable advantages: a) it may modify the alkyne reactivity to offer novel chemistry; b) it may serve as a desirable reaction site in products for further manipulations including elimination and various cross coupling reactions. Herein, we report gold-catalyzed 1,2-acyloxy migrations of terminally halogenated propargylic

\footnotetext{
${ }^{\dagger}$ Electronic Supplementary Information (ESI) available: experimental procedure, ${ }^{1} \mathrm{H}$ and ${ }^{13} \mathrm{C}$ NMR spectra, and the X-ray structure of compound 6a. See DOI: 10.1039/b000000x/

†We gratefully thank NSF (CAREER CHE-0969157), NIH (R01 GM084254) and UCSB for generous financial support and Dr. Guang Wu for kind help with X-ray crystallography.

This journal is $\odot$ The Royal Society of Chemistry [year]

Fax: (+01) (805) 893-4120; zhang@chem.ucsb.edu .
} 
carboxyates, which lead to efficient synthesis of bromo-/chlorodienes with excellent diastereoselectivities.

We initiated our study by using bromoalkyne $\mathbf{3}$ as the substrate. While trapping the anticipated gold carbenoid intermediate of type $\mathbf{C}$ was not successful, we were delighted by the isolation of bromodiene $4^{5,9}$ along with $\alpha$-bromoketone 5 and enone $\mathbf{6}$ when $\operatorname{IPrAuNTf}_{2}$ was used as catalyst (Table 1, entry 1). The formations of these products are rationalized in Scheme 3: unlike the lack of reactivities in the case of terminal alkynes, the bromo group selectively facilitates a 1,2-acetoxy migration via cyclic intermediate $\mathbf{D}$; the allyl cation $\mathbf{E}$ and its resonance form (i.e., F) thus generated then undergoes deprotonation and protodeauration, yielding diene $\mathbf{4}$ as the major product; hydrolysis of either $\mathbf{D}$ or $\mathbf{4}$ affords $\alpha$ bromoketone $\mathbf{5}$ or $\mathbf{6}$, respectively. Catalyst screening quickly revealed that $\mathrm{Ph}_{3} \mathrm{PAuNTf}_{2}$ was optimal, and $82 \%$ yield of $\mathbf{4}$ was isolated after only 10 min reaction, and hydrolysis side reactions were avoided under anhydrous conditions. Notably, the $(1 Z, 3 E)$-isomer of $\mathbf{4}$ was formed with excellent diastereoselectivity. The assigned geometry was corroborated by the structure of $\mathbf{8 e}$ (vide infra) secured by X-ray diffraction studies (Figure 1). Moreover, $\mathrm{PtCl}_{2}$ and Brønsted acid $\mathrm{HNTf}_{2}$ did not catalyzed the reaction.

The reaction scope was then promptly studied. As shown in Table 2, products with $\mathrm{R}^{1}=$ aryl or alkyl groups were formed in excellent yields. Alkyl groups with remote functional groups such as Br, TBSO, PhthN, and BnO (entries 3-6) were all well tolerated, and the corresponding bromodienes were isolated in excellent yields, and again only the $(1 Z, 3 E)$ geometric isomers were observed. In entries 8 and 9, pivalates instead of acetates were used, and the reactions proceeded equally well, suggesting that the acyl moiety could be readily modified. Much to our surprise, substrates containing azido groups did not react, and neither were those with closely positioned functional groups (e.g., $\mathrm{R}^{1}=\mathrm{CH}_{2} \mathrm{Br}$ or $\mathrm{OBn}$ ). Likely due to the acidity of the gold catalyst, substrates containing MOMO groups led to messy results. Although propargylic acetates containing a vinyl group $\left(\mathrm{R}^{1}=\right.$ but-3-enyl $)$ did not react, an electron-deficient enoate moiety was well accepted, leading to triene $\mathbf{8 g}$ in $88 \%$ yield. For substrates with secondary alkyl groups (e.g., isopropyl, cyclopentyl, and cyclohexyl) substituted at the propargylic position, no reaction was observed, which was presumably due to the difficulty in the formation of trisubstituted $\mathrm{C}-\mathrm{C}$ double bonds.

This ready formation of bromo-substituted dienes opened opportunities to study their synthetic potentials. To our surprise, they reacted poorly as dienes in the Diels-Alder reaction. Although under thermo conditions they did react with dienophiles such as $\mathrm{N}$ phenylmaleimide, the cycloadduct was not stable on silica gel columns; on the other hand, various Lewis acids (e.g., $\mathrm{TiCl}_{4}$ and $\mathrm{MeAlCl}_{2}$ ) were ineffective at ambient or lower temperatures, and the dienes were mostly recovered unreacted. The lack of rate acceleration by Lewis acids is likely due to the deactivation of the diene via acyl carbonyl group coordination. We reasoned that replacing the bromo group in the diene structure with a chloro should render cycloadducts more stable and, therefore, allow easier product isolation. To our delight, chlorodiene $\mathbf{8 j}$ was readily prepared from chloropropargyl ester $\mathbf{7 j}$ (Scheme 4). Notably, a relatively electron-rich benzoate was used in this case to enhance the diene reactivity, and the yield remained high albeit a slower reaction. Indeed, $8 \mathbf{j}$ was a suitable diene for the Diels-Alder reaction. For example, it reacted with dimethyl acetylenedicarboxylate upon heating to give highly substituted benzene 9 directly in $75 \%$ isolated yield; apparently, the initial cycloadduct underwent facile in situ aromatization via $\mathrm{HCl}$ elimination. Moreover, it reacted well with $N$-phenylmaleimide, affording enol ester 10 in a good yield. To our disappointment, it did not react with less reactive dienophiles such as ethyl acrylate. 
To our delight, the $\mathrm{Br}-\mathrm{C}\left(\mathrm{sp}^{2}\right)$ bond in 1-bromo-2-pivaloyldiene $\mathbf{8 h}$ participated in crosscoupling reactions readily, thus opening an efficient and highly flexible access to a range of carboxydienes, which are versatile substrates for organic synthesis. As shown in Scheme 5, $\mathbf{8 h}$ underwent smooth Kumada cross-coupling in the presence of $\mathrm{NiCl}_{2}$ (dppp), affording internal diene $\mathbf{1 1}$ in an acceptable yield. The use of pivaloyl instead of acetyl was beneficiary as it kept nucleophilic attack at the acyl group to the minimum extent even in the presence of strong nucleophiles such as $n$-butylmagnesium chloride and at the same time removed acidic $\alpha$-hydrogens. Similarly, the bromodiene proceeded well in SuzukiMiyaura ${ }^{10}$ and Sonogashira cross-coupling reactions under basic conditions, yielding aryldiene $\mathbf{1 2}$ and dienyne 13, respectively, in fairly good yields. Notably, while dienyl pivalate 11 could be prepared using our previously reported method, ${ }^{5}$ the synthesis of aryldiene 12 would be very low yielding due to a known side reaction; 5 moreover, pivaloyldienyne $\mathbf{1 3}$ has a uniquely conjugated structure, and a general synthesis ${ }^{11}$ of it and related structures has not been reported.

\section{Conclusion}

To overcome low reactivities of secondary aliphatic propargyl carboxylates containing a terminal alkyne in gold catalysis, we have demonstrated that attaching a $\mathrm{Br}$ or $\mathrm{Cl}$ group to the alkyne terminus could efficiently promote its participation selectively in gold-catalyzed 1,2-acyloxy migration. 1-Bromo/chloro-2-acyloxy-1,3-dienes are formed in high yields and typically in $10 \mathrm{~min}$. The reaction generally works very well with substrates with remote functional groups. Notably, the reaction was highly diastereoselective, and only the (1Z, $3 E$ )-isomers were observed. While these functionalized dienes are in general poor substrates for the Diels-Alder reaction, they participate readily in transition-metal catalyzed crosscoupling reactions including Kumada, Suzuki-Miyaura and Sonogashira, offering an efficient access to a much broader range of functionalized dienes.

\section{Supplementary Material}

Refer to Web version on PubMed Central for supplementary material.

\section{Acknowledgments}

We gratefully thank NSF (CAREER CHE-0969157), NIH (R01 GM084254) and UCSB for generous financial support and Dr Guang Wu for his kind help with X-ray crystallography. LZ thanks the Alfred P. Sloan Foundation for fellowship.

\section{Notes and references}

1. For reviews, see: a) Fürstner A, Davis PW. Angew. Chem., Int. Ed. 2007; 46:3410-3449. b) Arcadi A. Chem. Rev. 2008; 108:3266-3325. [PubMed: 18651778] c) Zhang L, Sun J, Kozmin SA. Adv. Synth. Catal. 2006; 348:2271-2296. d) Gorin DJ, Sherry BD, Toste FD. Chem. Rev. 2008; 108:3351-3378. [PubMed: 18652511] e) Hashmi ASK. Chem. Rev. 2007; 107:3180-3211. [PubMed: 17580975] f) Li Z, Brouwer C, He C. Chem. Rev. 2008; 108:3239-3265. [PubMed: 18613729] g) Patil NT, Yamamoto Y. Chem. Rev. 2008; 108:3395-3442. [PubMed: 18611054] h) Abu Sohel SM, Liu R-S. Chem. Soc. Rev. 2009; 38:2269-2281. [PubMed: 19623349]

2. For a review, see: a) Wang S, Zhang G, Zhang L. Synlett, 2010. 2010:692-706. for selected examples, see: b) Zhang L. J. Am. Chem. Soc. 2005; 127:16804-16805. [PubMed: 16316224] c) Wang S, Zhang L. J. Am. Chem. Soc. 2006; 128:8414-8415. [PubMed: 16802803] d) Zhang L, Wang S. J. Am. Chem. Soc. 2006; 128:1442-1443. [PubMed: 16448102] e) Marion N, DiezGonzalez S, de Fremont P, Noble AR, Nolan SP. Angew. Chem., Int. Ed. 2006; 45:3647-3650.

3. For selected examples, see: a) Miki K, Ohe K, Uemura S. J. Org. Chem. 2003; 68:8505-8513. [PubMed: 14575478] b) Johansson MJ, Gorin DJ, Staben ST, Toste FD. J. Am. Chem. Soc. 2005; 127:18002-18003. [PubMed: 16366541] 
4. For a computational study on both pathways, see: a) Correa A, Marion N, Fensterbank L, Malacria M, Nolan SP, Cavallo L. Angew. Chem., Int. Ed. 2008; 47:718-721. for a mechanistic study, see: b) Mauleón P, Krinsky JL, Toste FD. J. Am. Chem. Soc. 2009; 131:4513-4520. [PubMed: 19275228]

5. Li G, Zhang G, Zhang L. J. Am. Chem. Soc. 2008; 130:3740-3741. [PubMed: 18311985]

6. For gold catalysis using haloalkynes as substrates, see: a) Mamane V, Hannen P, Fürstner A. Chem., A Eur. J. 2004; 10:4556-4575. b) Staben ST, Kennedy-Smith JJ, Huang D, Corkey BK, LaLonde RL, Toste FD. Angew. Chem., Int. Ed. 2006; 45:5991-5994. c) Linghu X, Kennedy-Smith J, Toste F. Angew. Chem., Int. Ed. 2007; 46:7671-7673.

7. For a Pt-catalyzed case where an ester group is attached to the alkyne terminus (i.e., alkynoates), see: Prasad BAB, Yoshimoto FK, Sarpong R. J. Am. Chem. Soc. 2005; 127:12468-12469. [PubMed: 16144376]

8. a) Buzas A, Gagosz F. Org. Lett. 2006; 8:515-518. [PubMed: 16435873] b) Buzas AK, Istrate FM, Gagosz F. Tetrahedron. 2009; 65:1889-1901.

9. For previous gold-catalyzed diene formation, see: a) Wang SZ, Zhang LM. Org. Lett. 2006; 8:45854587. [PubMed: 16986956] b) Buzas AK, Istrate FM, Gagosz F. Org. Lett. 2007; 9:985-988. [PubMed: 17295496] c) Dudnik AS, Schwier T, Gevorgyan V. Tetrahedron. 2009; 65:1859-1870. d) Dudnik AS, Schwier T, Gevorgyan V. J. Organomet. Chem. 2009; 694:482-485. [PubMed: 20161695]

10. Billingsley K, Buchwald SL. J. Am. Chem. Soc. 2007; 129:3358-3366. [PubMed: 17326639]

11. For a sythesis of a related structure, see: Reisch J, Mester Z. Monatsh. Chem. 1983; 114:635-637. 


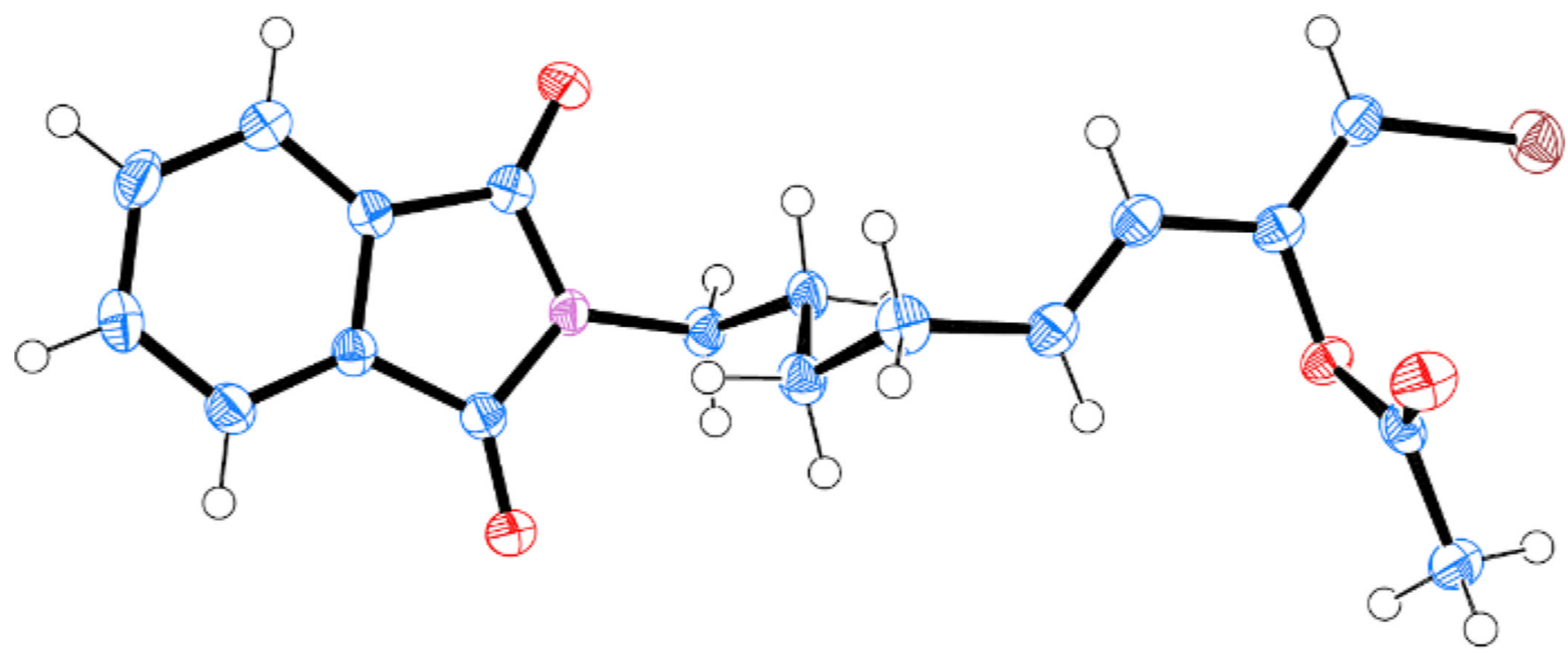

Figure 1.

ORTEP drawing of compound $\mathbf{8 e}$ 


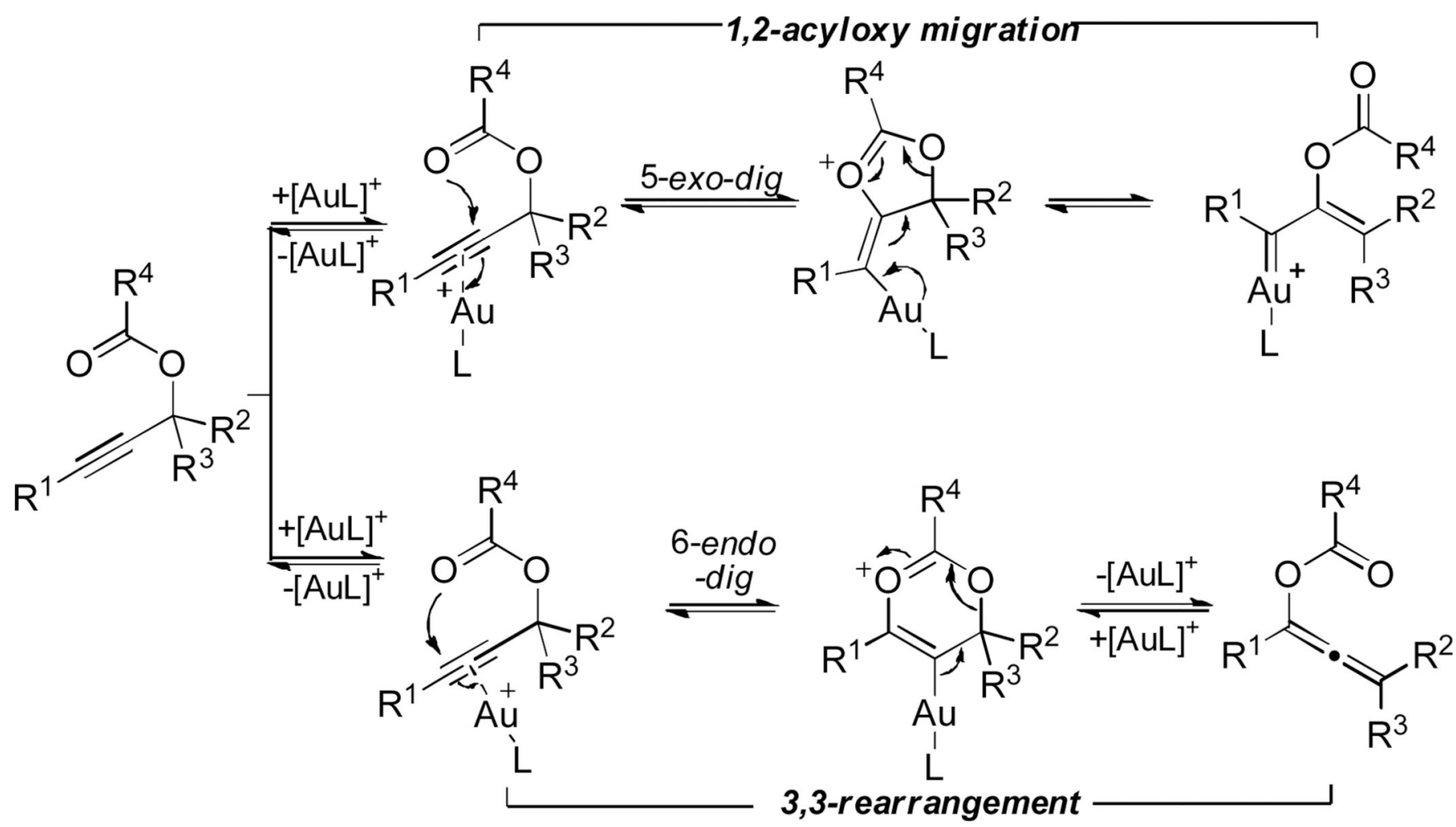

Scheme 1.

Two reaction pathways in gold-catalyzed reactions of propargylic carboxylates 


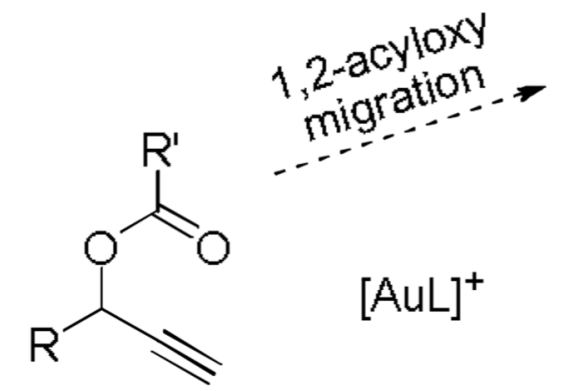<smiles>[R]C=C(C=[Te]I)OC([R])=O</smiles><smiles>[R]C=C=COC([R])=O</smiles>

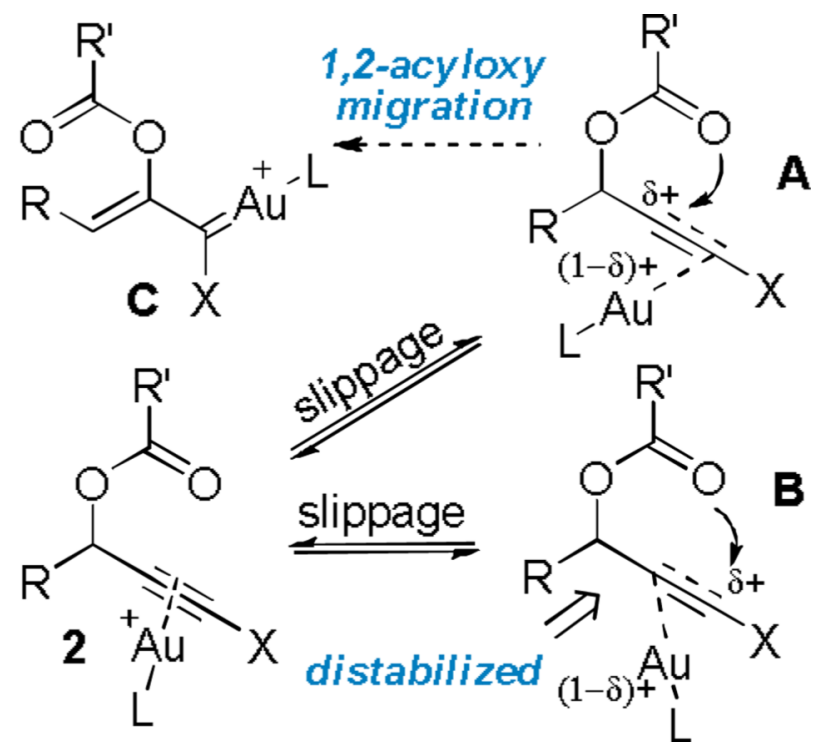

Scheme 2.

Terminally halogenated propargylic carboxylates as substrates 


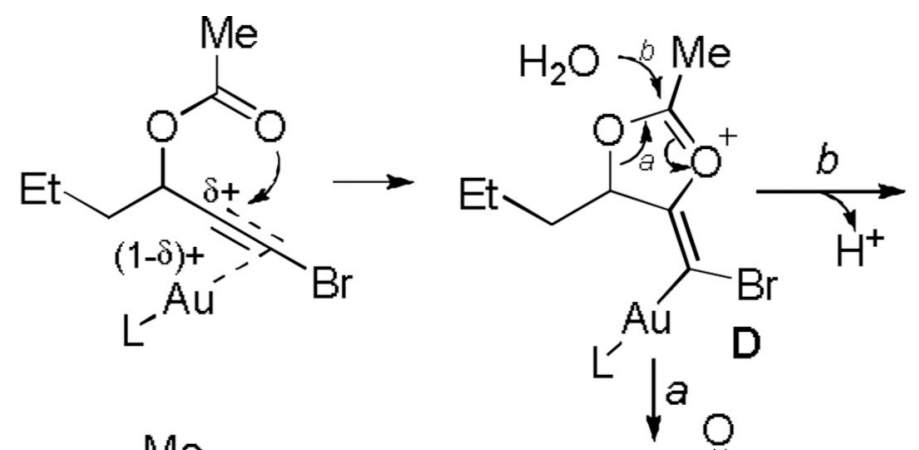

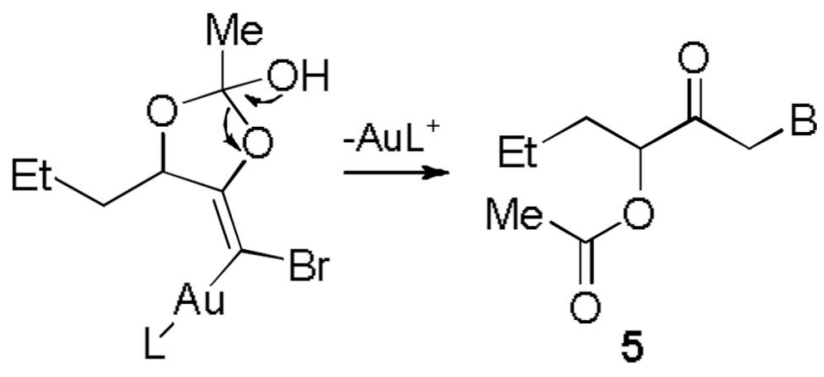

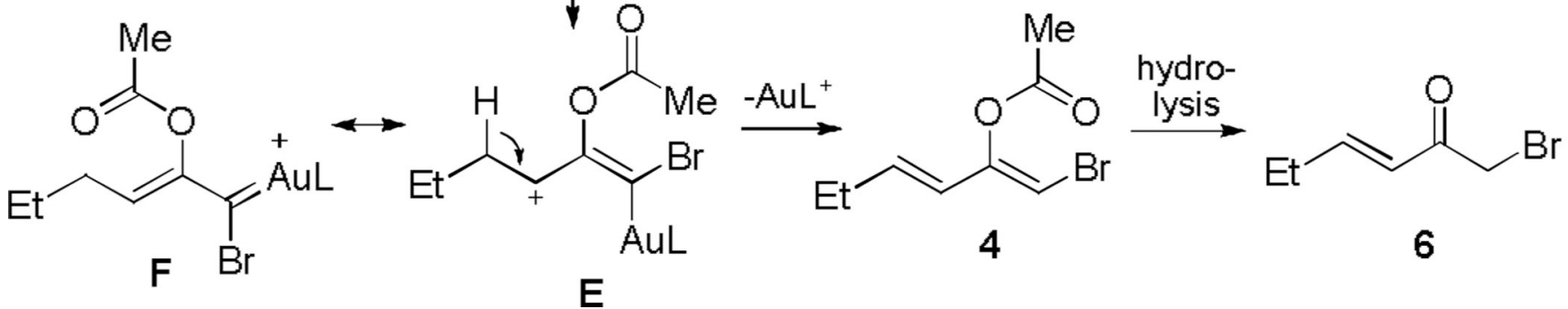

Scheme 3.

Proposed mechanism for the formations of 4-6 
<smiles>CC/C=C/C(=C/Cl)OC(=O)Br</smiles>

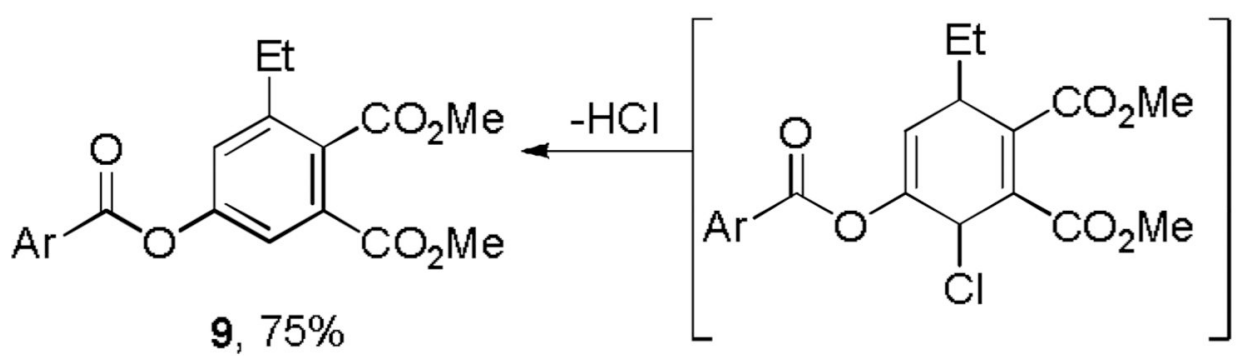<smiles>CC[C@H]1C=C(OC(=O)[Al])[C@@H](Cl)[C@H]2C(=O)N(c3ccccc3)C(=O)[C@@H]12</smiles>

Scheme 4.

Participation in Diels-Alder reactions 


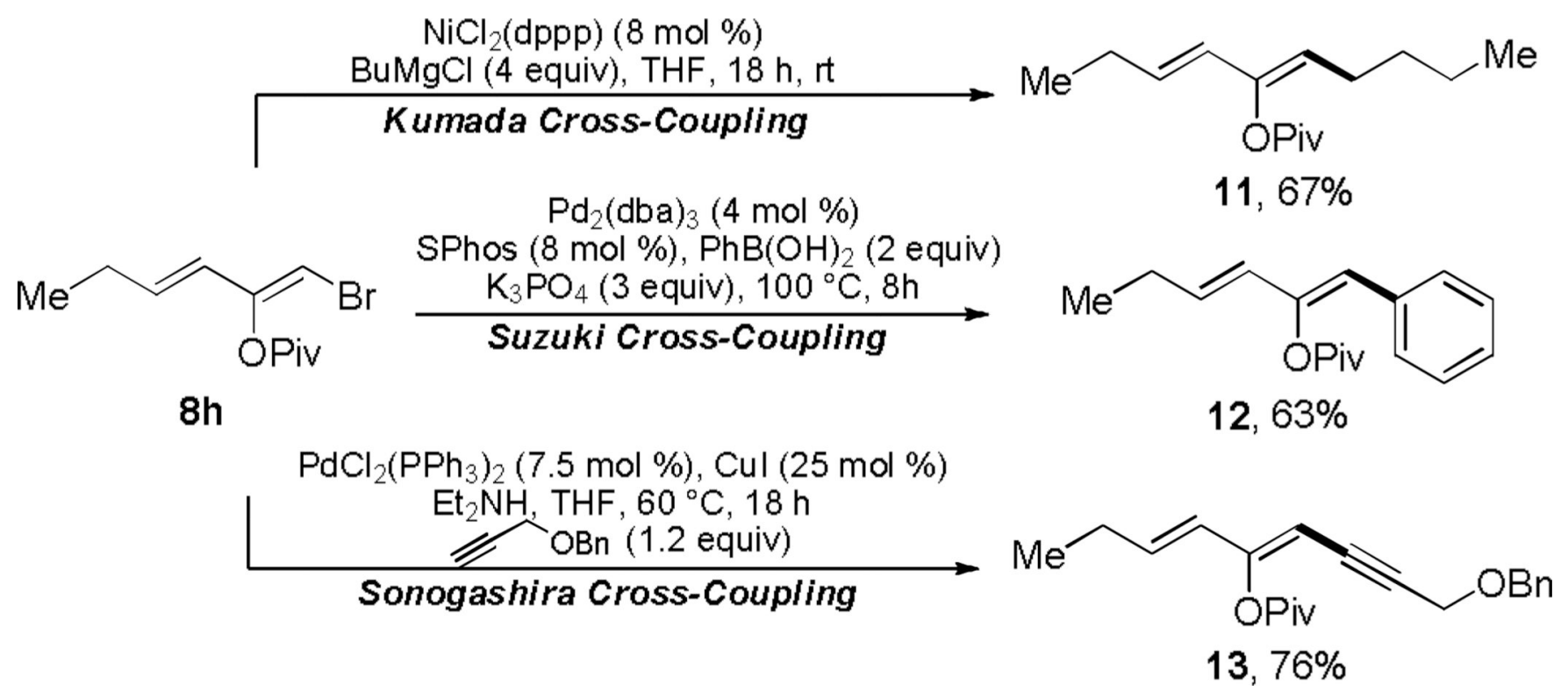

Scheme 5.

Participation in various cross-coupling reactions 
Table 2

Reaction scope studies ${ }^{a}$

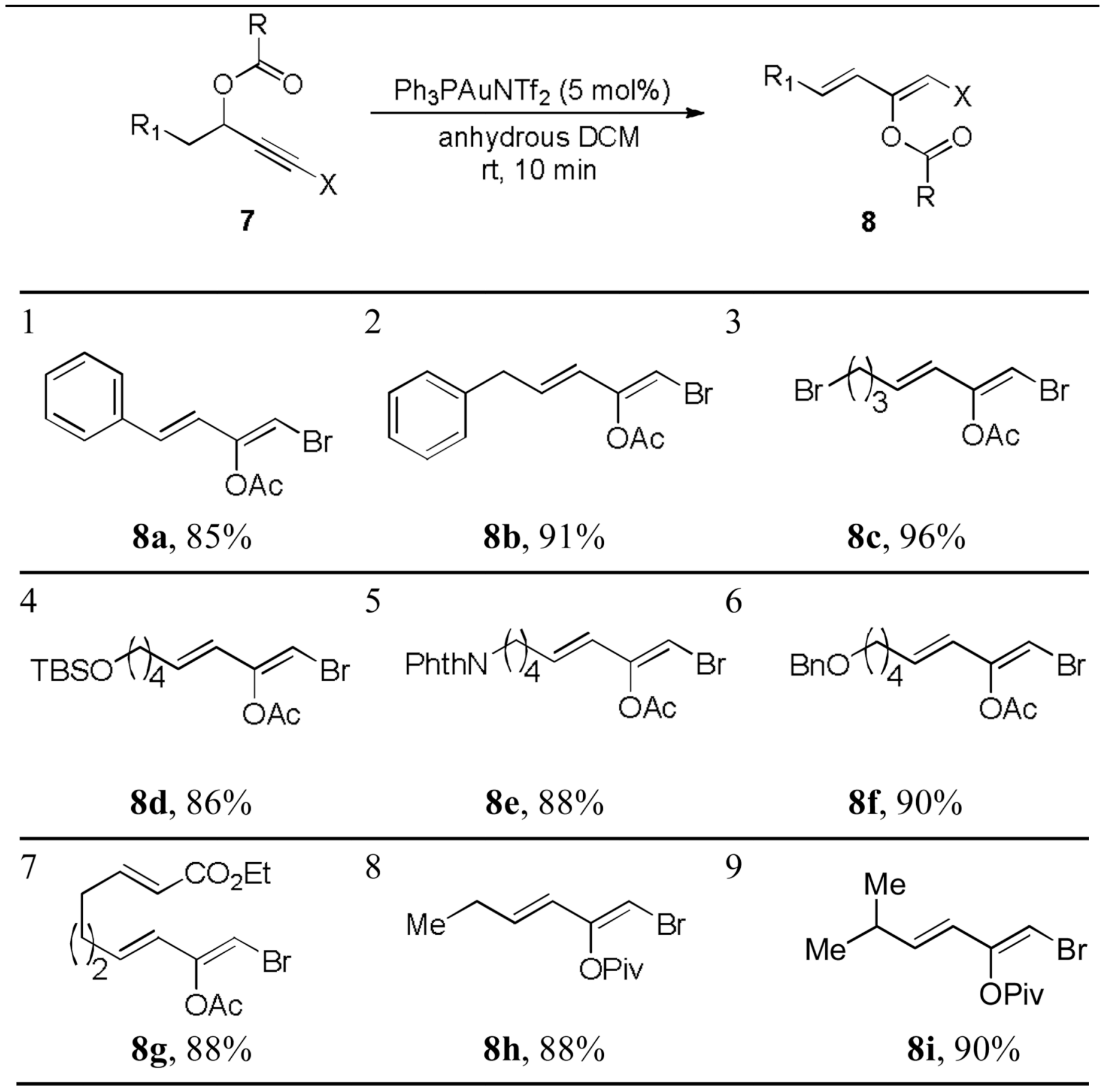

${ }^{a}$ The reaction concentration was $1 \mathrm{M}$. 